\title{
Partners in Local Resilience
}

\author{
ASHLEE JENSEN GRACE \\ Associate City Planner for the City of Denver Public Works Department \\ ashjen@umich.edu
}

ELIZABETH GIBBONS

Managing Director, American Society of Adaptation Professionals

bgibbons@iscvt.org

MATTHEW NAUD

Environmental Coordinator, City of Ann Arbor, Michigan

Mnaud@a2gov.org

JOHN CALLEWAERT

Emerging Opportunities Program Director, Graham Sustainability Institute,

University of Michigan

Corresponding Author and Mailing Address:

John Callewaert, Emerging Opportunities Program Director, Graham Sustainability Institute, University of Michigan, 625 E. Liberty, Suite 300, Ann Arbor, MI 48104 jcallew@umich.edu

Volume 4, 2016

http://dx.doi.org/10.3998/mjs.12333712.0004.002

\section{ABSTRACT}

Identifying mutually beneficial objectives for researchers and practitioners engaged in climate adaptation efforts can often be a challenge. Differences can occur in terms of motivations, objectives, scale, and decision-making authority.

Drawing on the experience of researchers and practitioners involved in a climate adaptation project focused on cities in the Great Lakes region, this paper provides an overview of the relationship between the University of Michigan's Graham Sustainability Institute and the City of Ann Arbor, Michigan. Utilizing a thick description 
for reviewing participant experience, this paper offers analysis of the effectiveness of two approaches to translational research: the boundary chain model and integrated assessment model. The paper also discusses the application of these translational research approaches and an iterative engagement process for enhancing the city's climate resiliency while strengthening the university's research and outreach efforts.

The deployment of these translational research models, coupled with numerous points of engagement between key university and city actors, has helped both entities emerge as national leaders in sustainability. Transferable lessons discussed include taking time to build trust among participants, the importance of proximity for being responsive, and utilizing organizational structures for supporting collaboration.

(Note: This manuscript was submitted as a feature editorial per the recommendation of the MJS editorial board.)

\section{Introduction}

Like many other cities around the globe, the City of Ann Arbor, Michigan (U.S.) faces numerous climate impacts that currently and will continue to affect the livelihood and safety of its residents. Located in a water-rich region in Southeast Michigan, approximately forty miles west of Detroit, a key concern for Ann Arbor is increasing precipitation, both in the form of seasonal trends (with fall alone experiencing a 27 percent increase from 1981-2010 compared to the previous 30 years) and also in the heaviest 1 percent of storms, which have increased in frequency and size (GLISA, 2013). Extended heat waves during the summer, shifting forest composition, and increasing variability in freeze-thaw cycles are other climate related impacts city staff expect to stress the built and natural infrastructure as well as the residents. However, unlike many other cities, Ann Arbor is home to a major research institution and hub of innovation: the University of Michigan (U-M). Ann Arbor has a residential population of 114,000, and U-M's 43,000 students and 41,000 faculty and staff play a significant role in shaping the character and composition of the city (University of Michigan Office of Budget and Planning, 2015, Palmer and Thomas, 2014).

Ann Arbor has a long history of planning around sustainability issues. The first energy plan was created in the 1980s, and more recently the city developed and 
approved a climate action plan and sustainability framework of 16 goals that were adopted as an element of the master plan. A recent reorganization created four service areas from 14 different departments and the systems planning unit (SPU) that integrates staff working on environment, energy, storm water, floodplains, GIS, infrastructure modeling, transportation, forestry, water quality, and capital improvements planning (ICLEI, 2011).

Relevant to the impacts of climate change and urban sustainability, the Graham Sustainability Institute (Graham) and its newly established Climate Center align the interdisciplinary interests of the U-M academic community with the interests of external partners. Graham established the Climate Center in response to a clear need for more climate related expertise and resources to be delivered to practitioners across the region. Core to Graham's climate efforts is its foundational program: the Great Lakes Integrated Sciences and Assessments (GLISA), which is a US National Oceanic and Atmospheric Administration funded collaboration between the U-M and Michigan State University (MSU). With these resources, Graham's Climate Center is uniquely situated as the go-to place for climate resources for cities in the region.

The collaborative relationship between the city's SPU and Graham is an effort that benefits both the city as a whole and the university research community. This collaboration directly enhances the city's climate adaptation planning efforts and informs how research at the university can be effectively translated into applied resources for regional practitioners and decision makers. To ensure the partnership is effective and mutually advantageous, Graham intentionally employs two translational research approaches for engaging with the city: the boundary chain model and integrated assessment. The use of these two approaches, which are iterative and informed by significant practitioner and stakeholder engagement, has helped both entities emerge as national leaders in their climate adaptation efforts.

Despite broad successes, there remain challenges inherent to navigating a complex relationship between the local jurisdiction of the city and the state-derived jurisdiction of the university. Included among these is the difficulty both entities face in raising awareness of their efforts among respective leadership and integrating their efforts across decentralized organizations. This paper will: (1) review how the relationship between these partners has developed, beginning with a more in-depth look at the two approaches of engagement; (2) discuss key lessons along the way; and (3) conclude with a discussion about key factors that make the successes of this partnership transferable to other university towns around the globe. 


\section{Theory of Engagement}

Communication of usable climate knowledge is central to transformative action on climate adaptation. Decision makers highlight the need for place-based climate science and options for responding to impacts (Bidwell et al., 2013). While there has been a rapid evolution of science-policy models toward addressing societal problems, there remains a persistent gap between the production and use of scientific knowledge (Kirchoff et al., 2013). To address this gap, Graham specifically seeks out partnerships with boundary organizations (watershed councils, municipalities, private sector organizations, non-governmental organizations, etc.) as a way to advance more broad dissemination and use of climate information (Dilling and Lemos, 2011, Guston, 2001).

Boundary organizations are important knowledge sources and brokers (Guston, 2001, Guston, 2007). They are agencies that stabilize the distinction between the production of science and its use in policy while facilitating supportive interactions between these two worlds (Kirchhoff et al., 2013). In this role, boundary organizations broker information between scientists and decision makers, often in an adaptable and relevant way that still makes the information acceptable and understandable for both sides (Lynch et al. 2008). This brokerage work is a resource-intensive process, and most of these organizations face limitations set by their available resources (Kirchhoff et al., 2013; McNie 2007). Therefore, the development of partnerships between two or more boundary organizations in the form of "boundary chains" is a useful approach to enhance these organizations' ability to provide climate information support to decision makers (Lemos et al., 2014). Linking boundary organizations helps share costs across several agencies while ensuring that each participant benefits from the resources and expertise available in the boundary chain. These linkages also aid in the organizations speaking in one voice, with common messages based on shared data. Chains are particularly beneficial when a process requires several steps of information customization before it is truly usable for the end-user (Lemos et al. 2014), as is common when translating data, information, and strategies between climate science organizations and decision makers. Working with boundary organizations aligns with the analyses of socio-ecological systems scholars who emphasize the importance of adaptive capacity for enabling institutions and networks to provide more inclusive and responsive decision making (Armitage and Plummer, 2010).

Responding to climate change, however, requires more than customized science and information. It demands integration across social, natural, and political sci- 


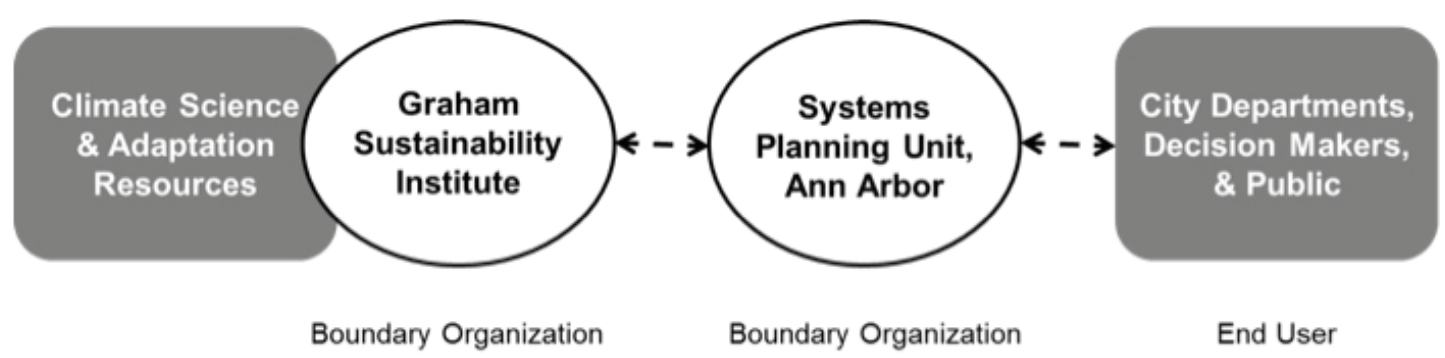

Figure 1: The relationship between Graham and SPU form a linked boundary chain model.

ence disciplines and the development of active exchanges and connections between decision makers and researchers. Integrative science and an improved understanding of climate change enable decisions to be based on the best available evidence. Without mechanisms to translate an improved scientific understanding into policy and management options, scientific advances can be destined to irrelevance, and city infrastructure investments can be misdirected, and without engagement with a wide group of stakeholders, options and strategies cannot be well-vetted prior to implementation (Lund et al., 2011, National Research Council, 2007). In light of these concerns, Graham employed an Integrated Assessment (IA) approach as an organizing framework for working with the SPU at the City of Ann Arbor.

IA offers an effective way to frame and guide decisions for sustainability problems that may lack consensus on the cause or solution. Through an innovative approach to analysis that includes engaging representatives from many impacted sectors and perspectives on a given issue, IAs collaboratively define problems, address diverse perspectives, use and share best-available information, and establish local and embedded partnerships with the goal of analyzing options for making positive change.

Figure 2 provides an overview of the IA process, involving both technical teams and stakeholders in an iterative process to define and clarify challenges and then generate solutions and decision support tools to address that challenge. The primary purpose of an IA is to serve as an "honest broker" and present information that expands and clarifies the scope of policy options in a way that allows a wide range of decision makers to make choices based on their preferences and values (Pielke, 2007). Participant identified benefits of IA include the generation of analytical reports and supporting data, modifying perspectives, creating new partnerships, changing processes, and leveraging additional resources (Lund et al., 2011, Grace et al., 2015). 


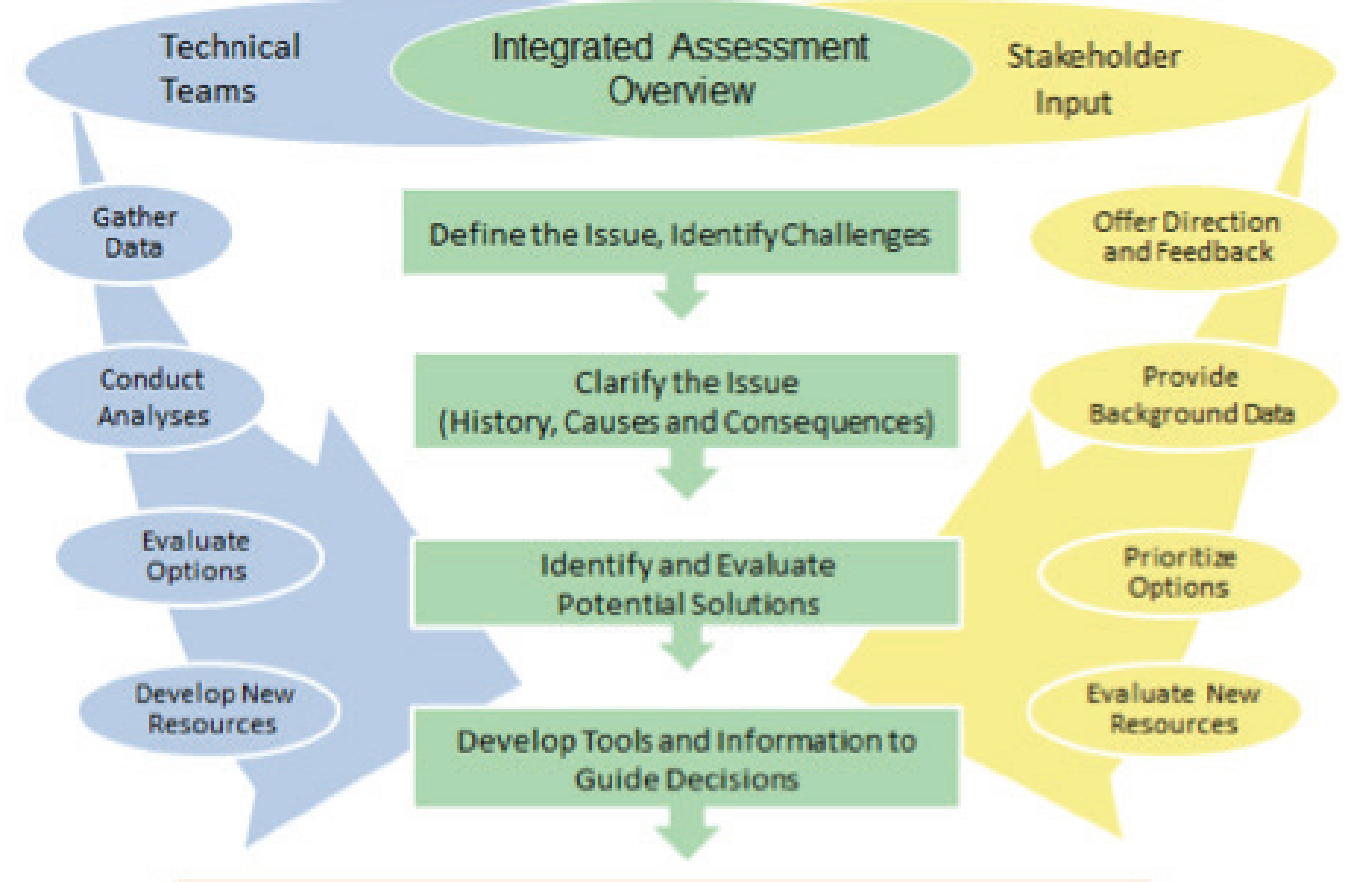

\section{Desired Outcome: Improved Capacity to Address the Issue}

Figure 2: Overview of the integrated assessment process

With the intention of assisting cities throughout the Great Lakes region in their climate adaptation efforts, Graham (prior to the establishment of the Climate Center) piloted an integrated assessment project, the Great Lakes Adaptation Assessment for Cities (GLAA-C), that worked collaboratively with staff and faculty from the GLISA program and utilized the boundary organization approach in order to achieve this goal. The GLAA-C project eventually provided the foundation for the Climate Center's Urban Adaptation Program. The project specifically sought out partnerships with cities due to the unique responsibilities they have for addressing vulnerable populations, the democratic mandate that they have to address the concerns of their populations, and their ability to act in partnership with private sector actors and civil society (Bulkeley, 2013; Rosenzweig et al., 2011). The project engaged six partner cities: Kingston and Thunder Bay, Ontario; Dayton and Toledo, Ohio; and Ann Arbor and Flint, Michigan. Among the six different city partnerships, the relationship with the City of Ann Arbor was especially unique given that the U-M is located in downtown Ann Arbor. While still an ongoing partnership, 
this paper will explore the different factors, including co-location and mutual gain, which have contributed to this successful climate-focused relationship and also the challenges that remain.

\section{Climate Engagement and Direct Outcomes between the University of Michigan and the City of Ann Arbor}

Prior to the start of their partnership as part of the project, staff at the City of Ann Arbor (many whom are U-M alumni themselves) often turned to U-M schools, programs, and faculty they were familiar with for one-off project support and guidance for a variety of sustainability initiatives. However, these informal collaborations were often created on an as-needed basis, and because they were often based on personal contacts, the benefits both U-M and Ann Arbor received were often contained to the one project and did not have a long-lasting or widespread impact.

This changed when the City of Ann Arbor and Graham staff began to interact for the purposes of the GLAA-C project. In 2010, Graham convened 39 city practitioners, adaptation experts, and researchers from around the region to discuss what was needed in the Great Lakes to help cities within the region better prepare for the impacts of climate change. This scoping meeting eventually resulted in the creation of the GLAA-C project. A representative from the city's SPU accepted Graham's invitation to attend the 2010 meeting and decided to participate in this meeting for several reasons. First, the SPU representative had a history of successful engagements with university staff and students on projects. Climate adaptation is a growing field with limited internal funding by the city, and this new engagement provided the opportunity to explore an ongoing relationship with the university around climate adaptation. Second, small upfront investments of city staff time have historically created useful projects or developed stronger networks that are useful as future opportunities arise.

The next major engagement occurred in November of 2012 when, as part of the GLAA-C project, Graham and the Institute for Sustainable Communities co-hosted a three-day workshop titled "Sustainable Communities Leadership Academy: Adaptation and Resilience for Great Lakes Cities." Thirteen city teams from across the region gathered in Ann Arbor to participate in the workshop. During the meeting, staff from the GLISA program presented climate information, and city participants shared their strategies and best practices for working on climate adaptation. Cities that participated in this workshop were invited to apply to be a part of an in-depth 
partnership through the GLAA-C project, which would include customized climate information (from GLISA) and adaptation support, and would include the opportunity to apply for a grant of $\$ 12,500$ for the city's own adaptation project.

Over the course of the in-depth engagement, SPU staff and Graham staff worked together to determine Ann Arbor's climate data and adaptation needs. As a result, Graham staff produced a climatology document and a summary projection and potential impacts document to aid SPU staff. These documents are representative of the mutually beneficial relationship that continued to grow during the project. While Graham staff knew they wanted to provide city practitioners with relevant climate information, they didn't know what data to include nor how to present it. Through feedback and guidance from SPU staff, the climatologies and summary documents ultimately displayed precipitation and temperature information in the form of trend lines and percentage change, and information was displayed in terms of seasonal changes. Ann Arbor's resulting climatologies pointed to important facts for the city about changing precipitation and temperature trends, such as increases in annual precipitation and warming winters (GLISA, 2013). SPU staff were able to share these important numbers with other city staff and externally with advisory boards and community groups. One SPU staff person even referred to the provision of these data as a tipping point that allowed the city to reach out to the community with facts - generated by the local university — which staff could trust to tell the local climate story. Due to these meaningful uses, Graham staff replicated the format for these climatologies and summary documents when creating similar climate resources for other in-depth city partners.

Beyond collaborating over the climatologies and summary documents, SPU and Graham staff worked together to organize two key events in 2013. The first of these was the "City of Ann Arbor Climate Change Workshop," which occurred in September of 2013. This half-day workshop, which Graham staff facilitated, brought together staff from different departments across the city to create a common understanding of the measured climate changes to date, forecasting climate changes for the region, facilitating a small group discussion on how climate change will affect city service delivery both with and across different service areas, and to discussing possible strategies and opportunities for action to adapt to these climate impacts. City staff cites this workshop and its associated outcomes as an important moment in helping shift the mindset of city employees to begin thinking about cross-departmental challenges and opportunities for action. Given their major involvement in organizing and facilitating the workshop, Graham staff also found this workshop to be an important milestone in the overall project because it pro- 


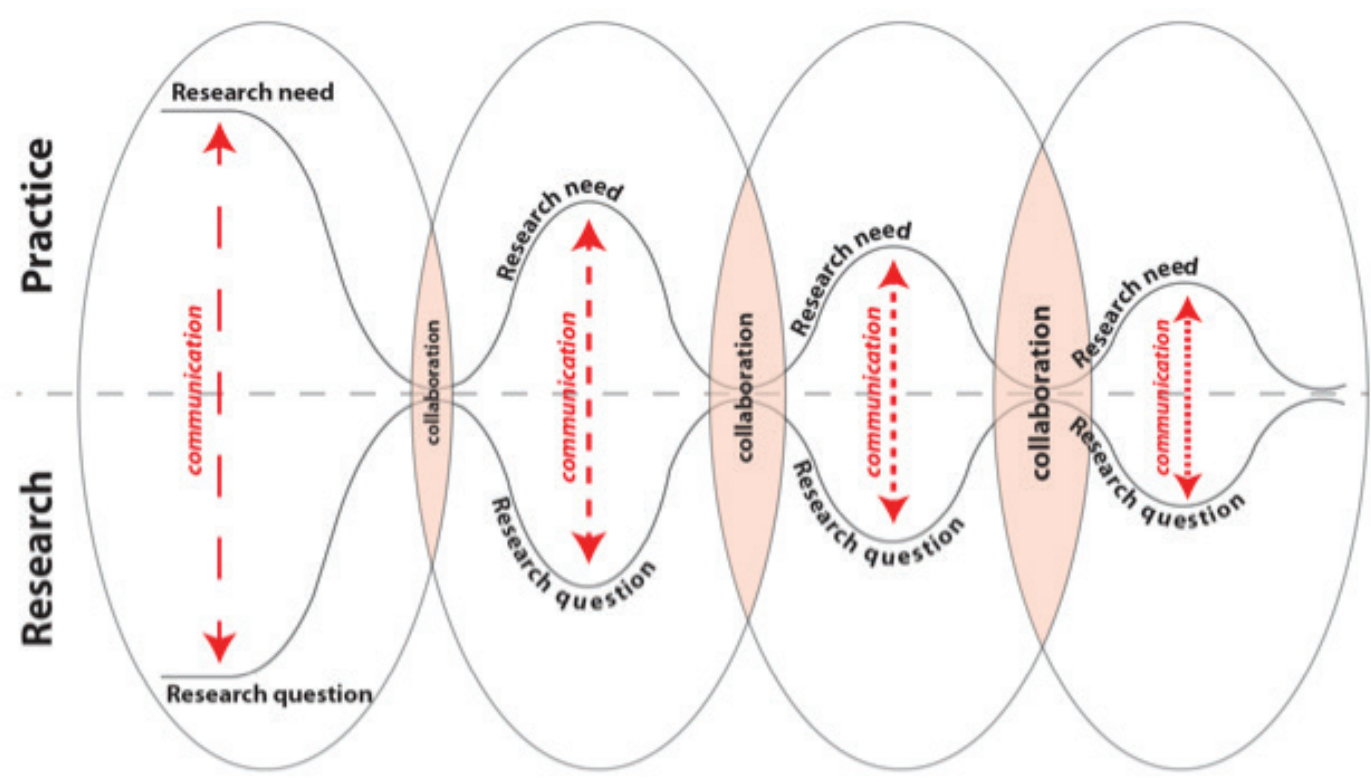

Figure 3: Ferguson's depiction of the iterative engagement process between research and practice.

vided Graham the occasion to test some of its rapid-vulnerability assessment tools and learn first-hand what the barriers and opportunities are for fostering multidepartmental conversations among city employees.

A major city project that Graham staff helped with was an initiative to create four climate adaptation awareness videos that not only aimed to educate Ann Arbor residents about climate change, but also to promote the city's recently launched Community Climate Partnership. In addition to funding the project, a Graham staff member was featured as a local expert in several of the videos. Graham staff also provided the city with facts and information to help tell the four video stories, which included the topics of climate adaptation, extreme storms, extreme heat, and changing forests.

\section{Partnership Benefits}

The boundary chain and integrated assessment approaches employed in this partnership ensured that each entity's broader organizational goals and capacity were enhanced. Figure 3 shows an idealized diagram of how the relationship between a practitioner and research community, similar to the one between Graham and the 
City of Ann Arbor, can evolve through an iterative engagement process (Ferguson, 2014) like an integrated assessment. This iterative engagement between Graham and SPU has allowed a strong network to develop among academics, students, and practitioners. Small successes play a key role by generating optimism in the engagement and a willingness to continue to invest social capital in the process. Another critical tenant to this engagement process is the important role co-production plays because it allows for the creation of resources which both communities in the partnership value.

Using Ferguson's diagram of iterative engagement (Figure 3), we can view the resulting benefits from the Graham and SPU partnership in terms of joint benefits, researcher-oriented benefits, and practitioner-oriented benefits. While in reality there were numerous, specific benefits each community gained through this partnership, we will describe the overarching and more generalized value that each group derived in the following paragraphs.

\section{Joint Benefit: Timely and Meaningful Exchange Between Research and Real World Application}

What emerged to be one of the most important components to this partnership was the safe space it established for an open and honest exchange between Graham researchers and real-world practitioners. According to one faculty researcher that was part of the GLAA-C project, having numerous opportunities to speak firsthand with city practitioners about climate adaptation introduced new questions, considerations, and a more complicated understanding of adaptation action and policy implementation at the city level. City staff echoed their appreciation of this exchange by stating that through direct engagement with faculty and climate experts, they were able to get answers to their specific, place-based questions instead of turning to a generalized study or piece of research that they would then have to interpret for their own purposes. The evolving relationship between Graham and SPU enabled a collaborative environment born out of mutual respect between the practitioners and researchers.

\section{Researcher Benefit: User-Inspired Climate Resources}

For Graham, an important benefit to working with the SPU staff was frequent guidance and feedback for the tools and resources Graham was creating. Throughout the academic and broader research community, there is an increasing need for 
user-inspired science resources. "User-inspired" is just one term for an emerging field of resources that have been categorized as 'practitioner-driven,' user-oriented, or translational. The relationship built between Graham and SPU created a space and opportunity for the development of these highly sought after user-inspired resources. Finally, the lessons gained from this experience continue to help the researchers, students, and Graham staff effectively translate climate science data into usable information for public consumption. Without the ongoing dialogue and candid responses SPU staff gave, the resources developed to-date would at least not be the same and likely would not be as effective.

\section{Practitioner Benefit: Legitimized Climate Data for Adaptation Efforts}

A major benefit this partnership brought to the city was to introduce the idea and elevate the staff conversation around climate adaptation, providing the knowledge base to understand it. Furthermore, working with Michigan, an internationally recognized research institution, helped to develop and legitimize the climatology data that directly supported the internal and community-wide discussions around climate adaptation. Because of the engagement with Graham, other SPU staff have built stronger networks in their areas of practice (e.g., storm water) and have become more engaged with other adaptation programs, such as the Garrison Institute's bi-annual "Climate, Cities, and Behavior" symposium.

\section{Partnership Challenges}

The partnership between SPU and Graham also faced numerous challenges. As with many partnerships, the most common challenges arose when the two communities were not aligned-particularly with respect to expectations and scale.

\section{Mismatched Motivation and Expectations}

While both the City of Ann Arbor staff and U-M researchers with the Graham Sustainability Institute were interested in furthering climate adaptation efforts at the municipal level, both have different reasons for this interest, and thus, disparity existed between their expected outcomes. For the most part, the researchers involved in this partnership were motivated from a theoretical standpoint and, through their work with the city, they hoped to advance the field of urban adaptation knowledge 
in the form of academically rigorous research so that lessons from this partnership could be transferred to a much broader audience. Meanwhile, SPU staff found value in this partnership because the resources and support Graham provided were intended to directly and immediately advance the city's adaptation knowledge base and inform their actions. Thus, misaligned expectations around partnership deliverables and project timelines initially added strain to the partnership. For instance, after the initial engagement with the city, it took nearly two years for Graham staff and researchers to come to the city with the proposal for how the two groups would work together and what outcomes could be expected. However, once the two groups began to meet more regularly and began to mutually understand each other's needs, it became easier to align priorities across the organizations and begin to produce products useful to both entities.

Another mismatch between academic and practitioner expectations occurred when Graham researchers wanted to advance their work by taking key city staff members' time for long interviews. Without a clear understanding of the value this would bring to the city, city staff was hesitant to devote their time or commit their colleague's time. Another aspect to this challenge is that the Graham research team was comprised of a group of faculty researchers who had diverse research areas and commitment levels. As a result, the city felt the value of engaging with Graham researchers was inconsistent as some faculty members tended to produce more direct benefits to the city than others. Overall, striking a balance between researcher and practitioner needs and expectations was an ongoing concern throughout the project but one that was made easier to address as trust and relationships built over time.

\section{Misaligned Commitments to Climate Adaptation between the University and the City}

A second major challenge that continued to potentially undermine the city and Graham's combined efforts to enhance Ann Arbor's climate preparedness is that the City of Ann Arbor does not have jurisdiction over University of Michigan land because it is a state institution. Despite the fact that U-M makes up over 8 percent of land within the city (Woodhouse, 2013), the city cannot tax or regulate university property. When the university buys property, tax revenue to the city is reduced. When the university builds a new building, they do not have to comply with city stormwater codes that would require a private developer to manage a 100 -year storm. This presented major challenges when it came to discussing adaptation strategies such as stormwater management. In a region that had seen a 38 percent increase in its heaviest 1 percent of 
storms from 1958 to 2012 (United States Global Change Research Program, 2014), stormwater management through infrastructure provision and land use regulations are major priorities for the city. However, the university owns several pieces of land associated with major flooding events and corresponding damage, and yet the city is unable to require the university to mitigate these impacts.

As an entity housed within the University of Michigan, Graham finds itself in an interesting position. Research from Graham student and faculty groups has supported the city's claim that the university property is a major piece to the stormwater management puzzle in Ann Arbor. However, despite the fact that they are part of the University of Michigan, it is an ongoing challenge for Graham and other U-M units to influence the decision making of university administration.

\section{Mismatch between Authority within Organizations and Scale of Problem}

Another key mismatch that presents a challenge to the work both Graham and SPU have set out to accomplish is that the neither have the final authority over the action their respective institutions can take, yet comprehensive institutional action is vital for making significant progress toward true climate resilience in Ann Arbor. For the SPU staff, recent recognition and support of climate adaptation action has been more forthcoming from both city residents as well as other staff members. However, widespread awareness of Graham and SPUs efforts has yet to be achieved as evident in 2014 remarks by an Ann Arbor city council person who was quoted by a local newspaper, demanding better research support from the University of Michigan to help the city adapt to the impacts of climate change (Briere, 2014).

\section{Discussion: Transferable Lessons Learned}

Although there are numerous aspects to this partnership that are unique, general principles can be applied to similarly situated universities and towns throughout the globe.

\section{Building Trust Is an Iterative Process that Takes Time}

SPU staff was initially skeptical about the value this partnership would bring. Despite the energy and enthusiasm around the 2010 meeting in which Graham staff 
convened researchers and practitioners to discuss the university's climate research work, the lack of immediate action following that gathering reinforced the view of city staff that academics often do not work on a real-world schedule. However, once engagement gained momentum with more regular conference calls and meetings in which climate scientists were asking city staff what questions they had about adaptation, trust began to build. Further support through the development of the climatologies and the increasing frequency of useful regional workshops and trainings solidified city practitioner trust in working with Graham. These documents and support services ensured the city that in exchange for offering their time and perspective, they would receive equal (or more) value from the partnership. The city staff was more willing to take risks with their own time and ask for other staff time with a higher expectation that useful products would be developed.

The iterative nature of the partnership (and a key characteristic of the integrated assessment approach) also facilitated the development of trust on behalf of both parties. Working collaboratively to define and redefine the questions that drove this multi-year engagement meant both sides learned how to listen to and learn from one another. As a result, initially simple questions — such as "What resources do cities need to adapt to climate change?"- - evolved into more sophisticated questions, including "How do you motivate the public to actively manage stormwater on their own property?" and "How can the city's tree canopy master plan be used to alleviate flooding in low income areas while also improving community health?" These questions reflect the evolution of more nuanced and complicated discussions that occurred between SPU staff and Graham researchers over time.

Most importantly, the time invested in building this trust has ensured that the partnership will continue to last past the initially conceptualized period of engagement. While early interactions were more intentional in their effort to create a partnership, the consistent and positive interaction between SPU staff and Graham over time has meant that the two have become natural allies in working together to answer challenging climate questions. For example, Graham is interested in pursuing efforts to build a broader regional network of urban practitioners working on climate adaptation at the municipal level. As a first order of action, Graham staff contacted SPU staff to not only gauge their interest in joining the network but to ask for their continued partnership and support in building this network. SPU staff was immediately interested in continuing to build on their mutually beneficial relationship with Graham and even took on the role of advocating for this regional network among their own professional community: the Urban Sustainability Directors Network (USDN). USDN is a peer-to-peer network that supports the connection, 
alignment, and production of innovative sustainability practices across 130 cities in the United States and Canada and has a growing interest in the role of regional networks in developing and disseminating innovation in cities. Graham and SPU staff, including the SPU staff member who plays a leadership role at USDN, along with other USDN Great Lakes cities, are currently exploring how to build a Great Lakes Climate Network that will add value to a network of cities and research institutions throughout the region.

\section{Co-location Allows for Many Points of Contact}

Beyond the numerous resources and workshops, the close physical proximity between Graham and the City of Ann Arbor created many opportunities for more informal engagement between the two. Due to Graham's offices being located only a few blocks from City Hall where SPU staff work, many meetings between the two groups were able to take place in-person instead of over the phone. Many Graham staff members are also City of Ann Arbor residents and thus have been able to participate in city commissions and groups. Several Graham staff and affiliates have served on commissions, including the Park Advisory Commission, the Environmental Commission, and the Energy Commission. A Graham climatologist is also part of Ann Arbor's Technical Oversight Advisory Group which provides guidance and assistance for several city wet weather projects. As a result, Graham staff is often personally invested in enhancing the city's well-being. These multiple points of formal and informal engagement also continue to build trust and respect between the two entities.

\section{Similar Organizational Structures Enable Similar Facilitator Roles}

Finally, it is important to discuss that Graham and SPU are both able to play similar roles as facilitators and conveners within their given institutions. As a department under the provost's office at the University of Michigan and as an institute that is working on the broad topic of sustainability, Graham is able to convene faculty researchers from a wide variety of fields. For instance, the Great Lakes Adaptation Assessment for Cities project was comprised of faculty members from the fields of urban planning, natural resource and environmental management, public health, public policy, and atmospheric sciences. Similarly, the SPU brings together issue experts in environment, energy, storm water, forestry, GIS, infrastructure modeling, non-motorized transportation, capital improvement planning, and interns. This in- 
tegrated unit serves as the core sustainability shop for the city and allows for more ready access to key staff working on sustainability issues.

Both Graham and the SPU also serve as boundary organizations that help broker the transfer of information between each other their respective institutions. For instance, SPU translates city politics and issues related to climate adaptation into questions that Graham can turn into valuable research questions for faculty members to investigate. Similarly, Graham is able to take the work researchers produce and translate it into meaningful information that SPU can take back to relevant departments for integration in decision making and planning procedures.

\section{Conclusion}

While the Graham Sustainability Institute may have been the first to initiate the partnership with the City of Ann Arbor's SPU, it proved to be mutually beneficial and a partnership that merited time and investment from both entities. Combining the boundary chain approach with the integrated assessment ensured that the partnership was dynamically evolving to meet both entities' needs by strengthening the trust and collaboration between the two groups. Working together has also been instrumental in helping each group's respective institutions emerge as national leaders in the field of climate adaptation. This is evident by the fact that both Graham and SPU staff are frequently given opportunities to share their adaptation strategies and lessons learned at local, state-wide, regional, and national conferences and meetings. However, despite these successes, inherent challenges remain, yet these too are integral to this partnership because they offer continued reasons to collaborate and problem-solve.

\section{Works Cited:}

Armitage, D., and R. Plummer. Adaptive Capacity and Environmental Governance. Berlin: Spring, 2010.

Bidwell, D., T. Dietz, and D. Scavia. "Fostering Knowledge Networks for Climate Adaptation." Nature Climate Change, 2013, 610-611.

Briere, S. "Advice for Schlissel: Tear down This Wall.” The Ann, September 5, 2015. Accessed April 26, 2015. http://www.theannmag.com/advice-for-schlissel-tear-down-this-wall/.

Bulkeley, H. Cities and Climate Change. New York, NY: Routledge, 2013.

Dilling, L., and M. Lemos. "Creating Usable Science: Opportunities and Constraints for Climate 
Knowledge Use and Their Implications for Science Policy." Global Environmental Change 21, no. 2 (2011): 680-89.

Ferguson, D., J. Rice, and C. Woodhouse. Linking Environmental Research and Practice: Lessons from the Integration of Climate Science and Water Management in the Western United States. Tucson, AZ: Climate Assessment for the Southwest, 2014.

Grace, A., E. Gibbons, and J. Callewaert. "Moving Urban Adaptation Forward in the Great Lakes." Michigan Journal of Sustainability 3 (2015).

Great Lakes Integrated Sciences and Assessments (GLISA). Historical Climatology: Ann Arbor, Michigan. In: Great Lakes Station Climatologies. 2013. Accessed December 9, 2015. http:// glisa.umich.edu/media/files/AnnArborMI_Climatology.pdf.

Guston, D.H. "Boundary Organizations in Environmental Policy and Science: An Introduction." Science, Technology, \& Human Values 26, no. 4 (2001): 399-408.

Guston, D.H. Between Politics and Science: Assuring the Integrity of Productivity of Research. Cambridge: Cambridge University Press, 2007.

ICLEI. Fact Sheet: How 38 Local Governments Fund Sustainability Staff and Operations. 2011. Accessed April 21, 2015. http://www.icleiusa.org/library/documents/ICLEI_Sustainability_ Funding_Fact_Sheet.pdf.

IPCC. Final Draft Report of the Working Group II Contribution to the IPCC Fifth Assessment Report Climate Change 2014: Impacts, Adaptation, and Vulnerability. New York, NY: Cambridge University Press, 2013.

Kirchoff, C., M. Lemos, and S. Dessai. "Actionable Knowledge for Environmental Decision Making: Broadening the Usability of Climate Science." Annual Review of Environment and Resources 38 (2013): 393-414.

Lemos, M., C. Kirchoff, C. Kalafatis, D. Scavia, and R. Rood. "Moving Climate Information off the Shelf: Boundary Chains and the Role of RISAs as Adaptive Organizations." Weather, Climate, and Society 6, no. 2 (2014): 273-85.

Lund, K., K. Dinse, J. Callewaert, and D. Scavia. "Benefits of Using Integrated Assessment to Address Sustainability Challenges." Journal of Environmental Studies and Sciences 1, no. 4 (2011): 289-95.

Lynch, A.H., R. Tryhorn, and R. Abramson. "Working at the Boundary: Facilitating Interdisciplinarity in Climate Change Adaptation Research." Bulletin of the American Meteorological Society 89 (2008): 169-79.

McNie, E.C. "Reconciling the Supply of Scientific Information with User Demands: An Analysis of the Problem and Review of the Literature." Environmental Science and Policy 10, no. 1 (2007): 17-38.

National Research Council. Analysis of Global Change Assessments_Lessons Learned. Washington, DC.: National Academy Press, 2007.

Palmer, T., and L. Thomas. "University of Michigan: Human Capital Report Highlight-2014." 2014. Accessed April 5, 2015. http://hr.umich.edu/humancapital/Final\%202014\%20 HCR\%20for\%20website\%20.pdf

Pielke, R. The Honest Broker: Making Sense of Science in Policy and Politics. Cambridge: Cambridge University Press, 2007.

Rosenzweig, C., W. Solecki, S. Hammer, and S. Mehrotra. Climate Change and Cities: First Assessment Report of the Urban Climate Change Research Network. Cambridge: Cambridge University Press, 2011. 
United States Global Change Research Program. "National Climate Assessment Full Report." 2014. Accessed March 30, 2015. http://nca2014.globalchange.gov/\#menu-report.

University of Michigan Office of Budget and Planning. "The Michigan Almanac." 2015. Accessed April 6, 2015. http://obp.umich.edu/wp-content/uploads/almanac/Almanac_Jan2015.pdf.

Woodhouse, K. "University of Michigan Expansion: Buying Land in Ann Arbor Raises Questions about Tax Base." Ann Arbor News, February 10, 2013. Accessed December 9, 2015. http:// www.annarbor.com/news/university-of-michigan-land-acquisition-means-less-money-forthe-city-of-ann-arbor/. 